\title{
Effect of hydrogen peroxide and universal adhesive application on the bond strength of glass fiber posts
}

Fernando Dalitz, DDS, MSc ${ }^{1}$; Orides Ferrari de Oliveira Junior, DDS ${ }^{1}$; Raisa Carolina Hintz, DDS, MSc ${ }^{1}$; Gisele Maria Correr, DDS, MSc, PhD²; Leonardo Fernandes da Cunha, DDS, MSc, PhD²; Carla Castiglia Gonzaga $\mathrm{DDS}, \mathrm{PhD}^{2}$

${ }^{1}$ Graduate student, Graduate Program in Dentistry, Universidade Positivo, Curitiba, PR, Brazil.

${ }^{2}$ Professor, Graduate Program in Dentistry, Universidade Positivo, Curitiba, PR, Brazil.
Corresponding author: Carla Castiglia Gonzaga Universidade Positivo

Rua Prof. Pedro Viriato Parigot de Souza, 5300 - 81280-330 Curitiba - PR - Brasil Phone: (5541) 3317-3180

Fax: (5541) 3317-3082

E-mail: carlacgonzaga2@gmail.com

Received: July 25, 2017

Accepted: November 23, 2017
Aim: This study aims to evaluate the effect of different surface treatments on the bond strength of glass fiber posts. Methods: Ninety unirradicular premolars had their crowns removed and were endodontically treated. After $24 \mathrm{~h}$, post spaces were prepared and the roots $(n=15)$ were divided into six groups according to the post surface treatment: NT - no treatment, UA - universal adhesive (Single Bond Universal), SUA - silane (Prosil), followed by universal adhesive, $\mathrm{H}-\mathrm{H}_{2} \mathrm{O}_{2}$ (Whitness HP Maxx, 35\%, gel, 1 min), HUA $-\mathrm{H}_{2} \mathrm{O}_{2}$, followed by universal adhesive, and $\mathrm{HSUA}-\mathrm{H}_{2} \mathrm{O}_{2}$, followed by silane and universal adhesive. The posts were cemented with dualcured resin cement (RelyX Ultimate). Bond strength was evaluated with pull-out test $(0.5 \mathrm{~mm} / \mathrm{mim})$ after $24 \mathrm{~h}$-storage in distilled water at $37^{\circ} \mathrm{C}$. Data were submitted to ANOVA and Tukey's test $(\alpha=5 \%)$. Results: HSUA group showed the highest bond strength value (236.5 N) followed by HUA (206.5 N), NT $(194 \mathrm{~N})$ and SUA (184 N) groups. UA group showed the lowest bond strength value $(60 \mathrm{~N})$. Conclusion: The use of $\mathrm{H}_{2} \mathrm{O}_{2}$, the silane application or the combination of these two treatments significantly increased bond strength values in groups in which the universal adhesive was used. A simplified procedure, such as cleaning with alcohol, can be recommended as surface treatment for the cementation of glass fiber posts.

Keywords: Post and core technique. Hydrogen peroxide. Dentin-bonding agents. 


\section{Introduction}

The dental restoration of endodontically treated teeth is considered one of the most critical restorative procedures, due to its complex nature and involvement of different specialties, such as Endodontics and Operative Dentistry. In some situations, particularly when there is significant loss of coronal tooth structure, the use of post and core systems is recommended. Glass fiber posts gained popularity in the last decades because are more flexible the metal post-cores and have elastic modulus similar to the dentin'. Moreover, since they can be adhesively cemented, masticatory stresses tend to be more evenly distributed in the root, resulting in fewer fractures or more favorable ones (not catastrophic), which can be subjected to repair-3.

In order to provide better retention for glass fiber posts, literature recommends using various surface treatment techniques, especially cleaning post surface with alcohol, conditioning with phosphoric acid or hydrofluoric acid, sandblast with aluminum oxide, silicatilization, silane and/or hydrophobic adhesive application, and, more recently, application of hydrogen peroxide $\left(\mathrm{H}_{2} \mathrm{O}_{2}\right)$ at different concentrations and times ${ }^{4-10}$.

Literature presents significant results regarding bond strength values to dentin when glass fiber posts were etched with hydrogen peroxide 5,9,11-14. Hydrogen peroxide at concentrations of $10 \%$ to $30 \%$ is known to effectively remove a surface layer of epoxy resin of glass fiber posts ${ }^{9}$. However, the application time of 5 to 20 minutes used in earlier studies can be considered long9,15. Few studies evaluated the use of $\mathrm{H}_{2} \mathrm{O}_{2}$ at different concentrations and lower application times ${ }^{5,8}$. It is also important to note that $\mathrm{H}_{2} \mathrm{O}_{2}$ is commonly used in dental practice for tooth whitening and, therefore, easily accessible for use as post surface treatment ${ }^{5}$. Moreover, it is important to emphasize that there is not yet enough information about the best concentration and application time of hydrogen peroxide in the surface treatment of glass fiber posts $5,9,11,13-15$.

Universal adhesives are simplified adhesive systems that can be used with both approaches (total- and s self-etching) and, because of this, are considered more versatile $^{16,17}$. These universal adhesives differ from current self-etching systems by incorporating monomers capable of producing a chemical bond with the dental tissues ${ }^{17,18}$. However, there is little information on the performance of these new universal adhesives. Chen et al. ${ }^{19}$ (2015) reported that the bond strength of a universal adhesive to dentin is not different from that of total- and self-etching adhesives. This study also showed that there was no statistical difference between the modes of application. A meta-analysis evaluated 10 studies in an attempt to establish what the best protocol for universal adhesives was, and reported no statistically significant difference between the strategies (total- and self-etching). Also, the bond strength to enamel was improved with prior conditioning with phosphoric acid universal when universal adhesives were used ${ }^{20}$.

Single Bond Universal is an example of universal adhesive, which also has silane in its composition. This would simplify the clinical steps, eliminating the need for silane application as a separate step during restorations repair protocols, for example ${ }^{21}$. Since the use of this universal adhesive with silane as surface treatment could influ- 
ence the bond strength of composites and ceramics ${ }^{21}$, it can be hypothesized that its use could also be an option for the surface treatment of glass fiber posts.

Thus, the objective of this study is to evaluate the effect of different surface treatments (universal adhesive application associated or not to the application of silane, with and without previous use of hydrogen peroxide) on the bond strength of glass fiber posts to root dentine using the pull-out test. The hypothesis tested is that the different surface treatments of the glass fiber posts would increase the bond strength values to root dentine.

\section{Material and Methods}

This study was approved by the Institutional Review Board (CAAE: 35991414.4.0000. 0093). Ninety human uniradicular premolars with anatomically similar root segments and fully developed apices were selected, cleaned and immersed in a neutral solution of chloramine $\mathrm{T} 0.5 \%$ at $4^{\circ} \mathrm{C}$ until use.

The roots were cut, with a diamond disk, under copious irrigation, to a uniform length of $15 \mathrm{~mm}$. The same operator instrumented and obturated all root canals. Root canal preparations were made with rotatory Protaper universal files (Dentsply Maillefer, Ballaigues, Switzerland). The irrigants used were $2.5 \% \mathrm{NaOCl}$ and $17 \%$ EDTA. After the final irrigation, the canals were dried with paper points (Roeko paper points; Coltene/ Whaledent, Cuyahoga Falls, Ohio, USA) and obturated with gutta-percha and AHPlus (Dentsply Maillefer, Ballaigues, Switzerland) using the Tagger's Hybrid technique.

Twenty-four hours after obturation, post spaces were prepared using Largo drills and the drill corresponding to the \#1 post (DC White Post, FGM, Joinville, SC, Brazil), maintaining an apical seal of $4 \mathrm{~mm}$. The roots were rinsed with physiological saline to remove remaining debris and then dried with absorbent paper points. The post spaces were then irrigated with and dried paper points. The drills were changed every 5 preparations.

The roots were randomly divided into six groups $(n=15)$, according to the following post surface treatment: NT - no treatment (control); UA - universal adhesive application (Single Bond Universal, 3M ESPE, St. Paul, MN, USA); SUA - silane coupling agent application (Prosil, FGM, Joinville, SC, Brazil), followed by universal adhesive (Single Bond Universal); $\mathrm{H}-\mathrm{H}_{2} \mathrm{O}_{2} 35 \%$ application (Whitness HP maxx, FGM, Joinville, SC, Brazil); $\mathrm{HUA}-\mathrm{H}_{2} \mathrm{O}_{2} 35 \%$ application, followed by universal adhesive; and $\mathrm{HSUA}-\mathrm{H}_{2} \mathrm{O}_{2}$ $35 \%$ application, followed by silane coupling agent and universal adhesive.

All glass fiber posts (DC White Post 1, FGM, Joinville, SC, Brazil) were cleaned with $70 \%$ alcohol and dried. Then, surface treatments were performed. The silane coupling agent was applied for $60 \mathrm{~s}$ and universal adhesive was applied for $20 \mathrm{~s}$ and light-cured for $10 \mathrm{~s}$. A LED curing light (Poly Wireless, Kavo, Joinville, Brazil), with irradiance of $1100 \mathrm{~mW} / \mathrm{cm}^{2}$ was used throughout the experiment. In groups with hydrogen peroxide application, the gel was applied to the surface of the post for $1 \mathrm{~min}$, the posts were washed with running water and dried. In HUA and HSUA groups, hydrogen peroxide was previously applied to the silane coupling agent and universal adhesive.

A layer of universal adhesive (Single Bond Universal, 3M ESPE) was applied to the post space; the excess was removed with paper points followed by $5 \mathrm{~s}$ of gentle air blast. 
The posts were coated with dual-cured resin cement (Rely X Ultimate, 3M ESPE, St. Paul, MN, USA) and slowly seated by finger pressure. Excess cement was immediately removed with an explorer and the cement was continuously light-cured for $40 \mathrm{~s}$. Afterwards, specimens were stored in a $37^{\circ} \mathrm{C}$ distilled water for $24 \mathrm{~h}$ and then subjected to the pull-out test. The pull-out test was performed using a universal testing machine (EMIC DL 2000 São José dos Pinhais, PR, Brazil) at a cross-head speed of $0.5 \mathrm{~mm} / \mathrm{min}$ until total displacement of the post.

The surfaces of the posts after the pull-out test were analyzed under a stereomicroscope with 57x magnification (SZX9, Olympus, Tokyo, Japan) to determine the areas of the posts with the presence of cement. The surfaces of each post were classified according to the percentage of adhering cement. The surfaces that had $50 \%$ or more of area covered with cement were classified as score 1 , while those surfaces that had less than $50 \%$ of the area covered with cement were classified as score 2.

Data were statistically analyzed using one-way ANOVA and Tukey's test with a significance level of $5 \%$.

\section{Results}

Mean values and standard deviations for bond strength according to the groups with different surface treatments for glass fiber posts are presented in Table 1. The results showed statistically significant differences regarding the surface treatments evaluated $(p<0.0001)$.

The HSUA group showed the highest bond strength values ( $236.5 \mathrm{~N}$ ) followed by HUA, NT and SUA groups, all statistically similar (206.5 N, 194 N and 184 N, respectively). $\mathrm{H}$ group showed bond strength values of $177.5 \mathrm{~N}$, statistically similar to HUA, NT and SUA and (206.5 N, $194 \mathrm{~N}$ and $184 \mathrm{~N}$, respectively). UA group showed the lowest bond strength values $(60 \mathrm{~N})$.

The results of the post surface analysis after the pull-out test are shown in Table 2. All groups had the majority of the failures classified as score 1 (50\% or more of the area covered with cement), indicating predominance of adhesive failure between resin cement and dentin.

Table 1. Mean values and standard deviations of bond-strength, according to the glass fiber surface treatment.

\begin{tabular}{lc}
\hline Surface treatment & Bond strength (N) \\
\hline No treatment (NT) & $194.0 \pm 54.2^{\mathrm{ab}}$ \\
\hline Universal adhesive (UA) & $60.0 \pm 18.8^{\mathrm{c}}$ \\
\hline Silane and universal adhesive (SUA) & $184.0 \pm 38.6^{\mathrm{ab}}$ \\
\hline Hydrogen peroxide (H) & $177.5 \pm 45.3^{\mathrm{b}}$ \\
\hline Hydrogen peroxide and universal adhesive (HUA) & $206.5 \pm 64.6^{\mathrm{ab}}$ \\
\hline Hydrogen peroxide, silane and universal adhesive (HSUA) & $236.5 \pm 70.1^{\mathrm{a}}$ \\
\hline Different superscript letters indicate statistically significant differences among the groups $(\mathrm{p}<0.05)$.
\end{tabular}


Table 2. Post surface analysis after pull-out test.

\begin{tabular}{lcc}
\hline Surface treatment & Score 1 & Score 2 \\
\hline NT & $88.9 \%$ & $11.1 \%$ \\
\hline UA & $70 \%$ & $30 \%$ \\
\hline SUA & $75 \%$ & $25 \%$ \\
\hline H & $88.9 \%$ & $11.1 \%$ \\
\hline HUA & $81,8 \%$ & $18.2 \%$ \\
\hline HSUA & $80 \%$ & $20 \%$ \\
\hline
\end{tabular}

\section{Discussion}

The hypothesis studied in the present work was rejected because the different surface treatments of glass fiber posts increased the bond strength values to root dentin. Four groups showed statistically similar bond strength values to the control group. Only the universal adhesive group showed lower bond strength values that were statistically different from the other groups and also from control group.

The use of different surface treatments in glass fiber posts aims to promote a better bond between the post and the resin cements used for luting. Glass fiber posts are covered by an epoxy resin layer that has high degree of conversion and few reactive sites for chemical adhesion to other resin materials ${ }^{22,23}$. This highly reticulated and low binding to the resinous material structure may be compensated by micromechanical retention on the surface of glass fiber posts created, for example, by $\mathrm{H}_{2} \mathrm{O}_{2}$, followed by silane coupling agent application $5,7,8$. The exposure of the glass fibers and the application of silane coupling agent improve the surface wettability and facilitate the chemical bond between fibers and resinous materials ${ }^{6,7,9}$.

Although literature reports that different surface treatments performed on the glass fiber posts can improve bond strength to dentin ${ }^{5,9,11-13,24}$, a systematic review of the literature that aimed to identify factors that may affect the retention of glass fiber posts to root dentin showed that endodontic treatment, resin cement application method and post surface treatment may significantly influence the retention of glass fiber post ${ }^{25}$. The study also indicated that the influence of these factors depends on the type of resin cement used, and this is more important when the posts are cemented with conventional resin cements. Self-adhesive cements were considered less sensitive to variations in the cementation technique when compared to conventional resin cements. The results of the systematic review showed that, for conventional resin cements, cleaning the posts increased significantly (by $43.4 \%$ ) the bond strength values when compared to silane coupling agent application without cleaning (ethanol, air abrasion, or phosphoric acid application). On the other hand, considering only the self-adhesive cements and all data (conventional and self-adhesive cements), the surface treatment of posts (cleaning or silanization) did not affect bond strength when compared with the use of these two treatments together ${ }^{25}$. 
These evidences may provide an explanation for the results found in the present study. A conventional resin cement (Rely X Ultimate, together with the Single Bond Universal adhesive system) was used to lute the glass fiber posts and all posts were cleaned with alcohol before the surface treatments were performed. As seen in Table 1, the bond strength values found for the control group (NT, no treatment, only cleaning with alcohol) were relatively high and they did not show significant differences in relation to other groups, except the group that used the universal adhesive (UA). This fact shows that only cleaning with alcohol can be sufficient to achieve a good bond with the resin cement, which can simplify the protocol to treat the surfaces of glass fiber posts.

Also thinking about the simplification, universal adhesives, which can be used in total-etch or self-etching approaches, have been used in direct and indirect esthetic restorative procedures. Among them, Single Bond Universal is the only one that has silane in its composition ${ }^{20}$. Thus, it was chosen in the present study for the luting of glass fiber posts and also as a surface treatment. To the authors' knowledge, no studies were found that evaluated the use of universal adhesives as surface treatment of glass fiber posts.

Silanes are adhesion promoters that contain two different reactive functional groups that can bond with various inorganic and organic materials. The hydrolysable functional groups react with hydroxyl groups on the surface of inorganic substrates, forming covalent Si-O-Si. Organic non-hydrolysable functional groups with a carbon double bond can polymerize with the resin monomers ${ }^{26}$. There must be a balance between the amount of exposed hydroxyl groups in the inorganic substrates and the hydrolysable silane functional groups. Thus, the quality of the Si-O-Si bond formed depends on the concentration of the silane solution ${ }^{26}$ and the substrate surface treatment protocol which determines the amount of exposed hydroxyl groups ${ }^{21}$.

The studies of Zaghloul et al. ${ }^{21}$ (2014) and Kalavacharla et al. ${ }^{27}$ (2015) evaluated the bond strength using a universal adhesive containing silane on ceramics and resin composite and showed that a silane coupling agent must be applied before the universal adhesive. A significant increase in bond strength values was observed for the groups where silane was applied in comparison with other groups without silane application. These results suggest that the silane component of the universal adhesive may not be enough to optimize substrate union with resin cement ${ }^{27}$.

These results corroborate the findings of the present study. In the group in which it was only used the universal adhesive (UA group) as surface treatment of the posts, it can be considered that the concentration of silane in the universal adhesive was not sufficient to react with the hydroxyl groups on the surface of the posts, which can, in turn, have impaired wettability of the surface and the interaction with the resin cement. The silane layer before the universal adhesive (SUA group) seems to have improved the chemical bond with hydroxyl groups exposed and the wettability of the post surface to interact with the cement.

In addition to silane coupling agent application as surface treatment of glass fiber posts, etching with phosphoric acid, hydrofluoric acid and hydrogen peroxide have also been reported in the literature ${ }^{28,29}$. Hydrogen peroxide has been used for the pre-treatment of glass fiber pins in concentrations varying from $10 \%$ to $30 \%$, being 
$24 \%$ the most cited in the literature $5,8,9,12,14,28,30$, in application times of 5 to $20 \min ^{9,15}$. The literature has shown higher bond strength values to dentin when glass fiber posts are treated with hydrogen peroxide ${ }^{5,9,11-14}$.

In this study a commercial gel for tooth whitening with $35 \%$ hydrogen peroxide was chosen because this material is commonly used in dental practice, not needing to be manipulated, and easily accessible for the surface treatment of posts. Another advantage is its application in short periods of time $(1 \mathrm{~min})^{8}$.

The results of the present work indicated that the use of hydrogen peroxide for the pre-treatment of glass fiber posts did not significantly increase the bond strength values when compared with the control group, where no treatment was performed other than cleaning with alcohol. However, although there was not statistically significant difference, higher bond strength values were obtained with the use of hydrogen peroxide, silane coupling agent and universal adhesive.

In conclusion, the surface treatment of glass fiber posts influenced the bond strength to root dentin. When the universal adhesive was used alone, lower bond strength values were found. The use of hydrogen peroxide, silane coupling agent application, or a combination of the two significantly increased bond strength values in groups in which the universal adhesive was used. Based on the results of the present study, a simplified procedure (cleaning with alcohol), without steps that can increase clinical time and technical sensitivity, can be recommended as surface treatment for the cementation of glass fiber posts.

\section{References}

1. Akkayan B, Gulmez T. Resistance to fracture of endodontically treated teeth restored with different post systems. J Prosthet Dent. 2002 Apr;87(4):431-7.

2. Barcellos RR, Correia DP, Farina AP, Mesquita MF, Ferraz CC, Cecchin D. Fracture resistance of endodontically treated teeth restored with intra-radicular post: the effects of post system and dentine thickness. J Biomech. 2013 Oct 18;46(15):2572-7. doi: 10.1016/j.jbiomech.2013.08.016

3. Verissimo C, Simamoto Junior PC, Soares CJ, Noritomi PY, Santos-Filho PC. Effect of the crown, post, and remaining coronal dentin on the biomechanical behavior of endodontically treated maxillary central incisors. J Prosthet Dent. 2014 Mar;111(3):234-46. doi: 10.1016/j.prosdent.2013.07.006.

4. Asakawa Y, Takahashi H, Kobayashi M, Iwasaki N. Effect of components and surface treatments of fiber-reinforced composite posts on bond strength to composite resin. J Mech Behav Biomed Mater. 2013 Oct;26:23-33. doi: 10.1016/j.jmbbm.2013.05.022

5. de Sousa Menezes M, Queiroz EC, Soares PV, Faria-e-Silva AL, Soares CJ, Martins LR. Fiber post etching with hydrogen peroxide: effect of concentration and application time. J Endod. 2011 Mar;37(3):398-402. doi: 10.1016/j.joen.2010.11.037

6. Guler AU, Kurt M, Duran I, Uludamar A, Inan O. Effects of different acids and etching times on the bond strength of glass fiber-reinforced composite root canal posts to composite core material. Quintessence Int. 2012 Jan;43(1):e1-8.

7. Liu C, Liu H, Qian YT, Zhu S, Zhao SQ. The influence of four dual-cure resin cements and surface treatment selection to bond strength of fiber post. Int J Oral Sci. 2014 Mar;6(1):56-60 doi: 10.1038/ijos.2013.83 
8. Menezes MS, Faria-e-Silva AL, Silva FP, Reis GR, Soares CJ, Stape TH, et al. Etching a fiber post surface with high-concentration bleaching agents. Oper Dent. 2014 Jan-Feb;39(1):E16-21. doi: 10.2341/12-270-L.

9. Monticelli F, Toledano M, Tay FR, Sadek FT, Goracci C, Ferrari M. A simple etching technique for improving the retention of fiber posts to resin composites. J Endod. 2006 Jan;32(1):44-7.

10. Machado FW, Bossardi M, Ramos TS, Valente LL, Münchow EA, Piva E. Application of resin adhesive on the surface of a silanized glass fiber-reinforced post and its effect on the retention to root dentin. J Endod. 2015 Jan;41(1):106-10. doi: 10.1016/j.joen.2014.09.014.

11. Mosharraf R, Ranjbarian P. Effects of post surface conditioning before silanization on bond strength between fiber post and resin cement. J Adv Prosthodont. 2013 May;5(2):126-32. doi: 10.4047/jap.2013.5.2.126.

12. Naves LZ, Santana FR, Castro CG, Valdivia AD, Da Mota AS, Estrela C, et al. Surface treatment of glass fiber and carbon fiber posts: SEM characterization. Microsc Res Tech. 2011 Dec;74(12):1088-92. doi: 10.1002/jemt.20999.

13. Shori D, Pandey S, Kubde R, Rathod Y, Atara R, Rathi S. To evaluate and compare the effect of different Post Surface treatments on the Tensile Bond Strength between Fiber Posts and Composite Resin. J Int Oral Health. 2013 Oct;5(5):27-32

14. Talebian R, Khamverdi Z, Nouri M, Kasraei S. Effect of ascorbic acid on bond strength between the hydrogen peroxide-treated fiber posts and composite resin cores. J Conserv Dent. 2014 May;17(3):220-4. doi: 10.4103/0972-0707.131779.

15. Elsaka SE. Influence of chemical surface treatments on adhesion of fiber posts to composite resin core materials. Dent Mater. 2013 May;29(5):550-8. doi: 10.1016/j.dental.2013.03.004.

16. Perdigao J, Loguercio AD. Universal or Multi-mode Adhesives: Why and How? J Adhes Dent. 2014 Apr;16(2):193-4. doi: 10.3290/j.jad.a31871.

17. Perdigao J, Munoz MA, Sezinando A, Luque-Martinez IV, Staichak R, Reis A, et al. Immediate adhesive properties to dentin and enamel of a universal adhesive associated with a hydrophobic resin coat. Oper Dent. 2014 Sep-Oct;39(5):489-99. doi: 10.2341/13-203-LR.

18. Hanabusa M, Mine A, Kuboki T, Momoi Y, Van Ende A, Van Meerbeek B, et al. Bonding effectiveness of a new 'multi-mode' adhesive to enamel and dentine. J Dent. 2012 Jun;40(6):475-84. doi: 10.1016/j.jdent.2012.02.012.

19. Chen C, Niu LN, Xie H, Zhang ZY, Zhou LQ, Jiao K, et al. Bonding of universal adhesives to dentine-Old wine in new bottles? J Dent. 2015 May;43(5):525-36. doi: 10.1016/j.jdent.2015.03.004.

20. Rosa WL, Piva E, Silva AF. Bond strength of universal adhesives: A systematic review and meta-analysis. J Dent. 2015 Jul;43(7):765-76. doi: 10.1016/j.jdent.2015.04.003.

21. Zaghloul H, Elkassas DW, Haridy MF. Effect of incorporation of silane in the bonding agent on the repair potential of machinable esthetic blocks. 2014 Jan;8(1):44-52. doi: 10.4103/1305-7456.126240.

22. Lassila LV, Tanner J, Le Bell AM, Narva K, Vallittu PK. Flexural properties of fiber reinforced root canal posts. Dent Mater. 2004 Jan;20(1):29-36.

23. Mazzitelli C, Ferrari M, Toledano M, Osorio E, Monticelli F, Osorio R. Surface roughness analysis of fiber post conditioning processes. J Dent Res. 2008 Feb;87(2):186-90.

24. Kim HD, Lee JH, Ahn KM, Kim HS, Cha HS. Effect of silane activation on shear bond strength of fiber-reinforced composite post to resin cement. J Adv Prosthodont. 2013 May;5(2):104-9. doi: 10.4047/jap.2013.5.2.104.

25. Skupien JA, Sarkis-Onofre R, Cenci MS, Moraes RR, Pereira-Cenci T. A systematic review of factors associated with the retention of glass fiber posts. Braz Oral Res. 2015;29. pii: S1806-83242015000100401. doi: 10.1590/1807-3107BOR-2015.vol29.0074. 
26. Matinlinna JP, Vallittu PK. Bonding of resin composites to etchable ceramic surfaces - an insight review of the chemical aspects on surface conditioning. J Oral Rehabil. 2007 Aug;34(8):622-30.

27. Kalavacharla VK, Lawson NC, Ramp LC, Burgess JO. Influence of Etching Protocol and Silane Treatment with a Universal Adhesive on Lithium Disilicate Bond Strength. Oper Dent. 2015 Jul-Aug;40(4):372-8. doi: 10.2341/14-116-L.

28. Majeti C, Veeramachaneni C, Morisetty PK, Rao SA, Tummala M. A simplified etching technique to improve the adhesion of fiber post. J Adv Prosthodont. 2014 Aug;6(4):295-301. doi: 10.4047/jap.2014.6.4.295.

29. Valdivia AD, Novais VR, Menezes Mde S, Roscoe MG, Estrela C, Soares CJ. Effect of surface treatment of fiberglass posts on bond strength to root dentin. Braz Dent J. 2014;25(4):314-20.

30. Khamverdi Z, Abbasi S, Habibi E, Kasraei S, Azarsina M, Ebadi S. Effect of storage time on microtensile bond strength between quartz fiber post and composite core after different post surface treatments. J Conserv Dent. 2011 Oct;14(4):361-5. doi: 10.4103/0972-0707.87198. 